\title{
The effects of alcohol on learned helplessness
}

\author{
MICHAEL F. LEY and LOWELL T. CROW \\ Western Washington University, Bellingham, Washington 98225
}

\begin{abstract}
Albino rats were subjected to inescapable shock or no-shock pretreatments with or without $1.5 \mathrm{~g} / \mathrm{kg}$ IP ethanol injections. Twenty-four hours later, all animals were trained in an FR-2 shuttlebox avoidance task with or without alcohol in a 2 by 2 by 2 experimental design. Alcohol was found to accentuate learned helplessness, but helplessness was observed in the shuttlebox after the shock pretreatment with or without alcohol if similar drug states accompanied each experience. Helplessness was not seen if drug states were shifted such that the avoidance conditioning took place in an alcohol state different from that of the inescapable shock experience. The results are discussed in terms of the role of the retrieval of emotionally conditioned cues in learned helplessness.
\end{abstract}

Dogs or rats placed in the situation of receiving inescapable and noncontingent electric shocks learn that the outcome of shocks is independent of all voluntary responses, thereby making the situation uncontrollable (Maier, Seligman, \& Solomon, 1969; Maier \& Seligman, 1976). The latter authors report that learning that events are uncontrollable constitutes the foundation for learned helplessness. Rats, pretreated with inescapable and uncontrollable shock, fail to escape or avoid shock in a subsequent twoway shuttlebox situation, an impairment dependent upon parameters of the pretreatment shocks and the nature of the subsequent task (Maier, Albin, \& Testa, 1973; Maier \& Testa, 1975). Other investigators have reported similar learning impairments using a variety of different testing situations (Altenor, Kay, \& Richter, 1977; Rosellini \& Seligman, 1976; Seligman \& Beagley, 1975; Seligman, Rosellini, \& Kozak, 1975).

The effects of alcohol on the rat's memory of shock avoidance has been shown to be complex, involving the phenomenon of state-dependent learning, an effect characterized by a lack of transfer across drug states from one task to another (Overton, 1964, 1966). These alcohol-induced impairments are thought to be associated with memory retrieval as opposed to direct drug depression of behavior or memory storage (Crow \& Watkins, 1976; Weingartner, Eich, \& Allen, 1973), and the effects are often associated with autonomic arousal (Crow \& Ball, 1975; Powell, Goodwin, Janes, \& Hoine, 1971).

If learned helplessness involves the retrieval of memories associated with the inescapable shock experience, and if these memories have an emotional element, the transfer across alcohol states may follow that found in the 2 by 2 avoidance learning design (Crow, 1966). If the alcohol state transfer effects

Appreciation is extended to Jerry Peterson and Joe Scheib for their technical assistance. are due to an impairment in memory retrieval, as opposed to nonassociative drug effects, the avoidance conditioning after pretreatment with shock should be enhanced by the shifts in alcohol states rather than impaired as in the traditional state-dependent learning design. If the alcohol state transfer effects are due to deficits in memory retrieval, as opposed to memory storage, the dissociation was expected to be asymmetrical (Crow \& Watkins, 1976). This later study indicated that in the 2 by 2 state-dependent learning design, asymmetry, the greater decrement in recall in the alcohol-to-sober change sequence than from the sober-to-alcohol change sequence, was eliminated by giving pyrazole prior to the initial training session. Since pyrazole inhibits alcohol oxidation, the authors concluded that the asymmetry was due to the absence of alcohol-associated cues in the test situation (cf. Crow \& Watkins, 1976). The present study was thus designed to explore the possibility of a state-dependent learned helplessness in the rat's shuttlebox behavior.

\section{METHOD}

\section{Subjects}

Fifty-six experimentally naive male albino Sprague-Dawley rats were used as subjects. The rats were obtained from the laboratory's own stock on hand and were 90-120 days old at the time of the experiment. The rats were individually housed and maintained on ad-lib food and water.

\section{Apparatus}

Inescapable shock was administered in a clear rectangular Plexiglas chamber, $.65 \mathrm{~cm}$ thick and $24.8 \mathrm{~cm}$ long $\times 9.0 \mathrm{~cm}$ wide $\times 8.3 \mathrm{~cm}$ high. Next to the sealed end of the restraining chamber was a $5.0-\mathrm{cm}$ piece of foam rubber covered by a $.4 \times 7.4 \times 7.0 \mathrm{~cm}$ fiberboard. To further restrict the movement of the rat, an adjustable piece of fiberboard, measuring $18.8 \mathrm{~cm}$ in length and ranging from 8.7 to $7.2 \mathrm{~cm}$ in width, was inserted diagonally into the restraining chamber. Holes were drilled on all four sides of the restraining chamber to aid in ventilation. The rat was placed inside the chamber, and the unsealed end was covered with adhesive 
tape to prevent the rat from backing out. The rat's tail was taped to a Plexiglas rod extending from the rear of the restraining chamber. Electrodes and electrode paste were fastened to the rat's tail with adhesive tape. A 1-mA shock was provided by an Applegate Model 250 shock generator. Sixty-decibel white and background noise was present during inescapable shock sessions.

Escape-avoidance learning was conducted in a $60.6 \times 22.4$ $\times 39.2 \mathrm{~cm}$ shuttlebox. The shuttlebox had a clear Plexiglas front and was divided in half by a $.6 \times 18.35 \times 37.6 \mathrm{~cm}$ piece of plywood that had a $6.1 \times 7.8 \mathrm{~cm}$ archway cut out of the center; the bottom of the archway was flush with the grid floor. Brass grids, $.3 \mathrm{~cm}$ in diameter, were connected to a Grason-Stadler Model E1064GS shock generator which provided a 1.0-mA shock. The shuttlebox was continuously illuminated by two $71 / 2-W$ red lights, which were not part of the CS. Fastened to the top of the shuttlebox was a buzzer. Training in the shuttlebox was conducted with $60-\mathrm{dB}$ white and background noise present.

\section{Drug Dosage and Administration}

The ethyl alcohol used was a $23.75 \%$ solution made from $95 \%$ ethanol and distilled water. The subjects received $1.5 \mathrm{~g} / \mathrm{kg}$ of the alcohol solution, which was injected intraperitoneally (IP). Although IP injections in the rat produce peak blood alcohol levels within $10 \mathrm{~min}$, the peak autonomic, central, and behavioral effects are not necessarily coincident (Kalant, 1971, p. 25). For example, body temperature changes in the rat as a result of IP ethanol injections of $1.5 \mathrm{~g} / \mathrm{kg}$ may be prolonged as much as 120 min after injection, while influences upon conditioned taste aversion may occur within 20 min with no discernible effect upon locomotor behavior (Linakis \& Cunningham, 1979). The depressive effects of ethanol upon the central nervous system occur by way of mechanisms not yet well understood, but the present dosage $(1.5 \mathrm{~g} / \mathrm{kg})$ and delay $(10 \mathrm{~min})$ are representative of studies employing moderately heavy amounts of alcohol in behavioral research on state-dependent learning of avoidance conditioning in the rat. In equal volumes to the alcohol injections, an isotonic saline solution was injected IP for the no-drug conditions.

\section{Procedure}

The rats were assigned randomly into two groups, an inescapableshock group $(n=28)$ and a naive group $(n=28)$. The rats in each group were further subdivided into one of four drugtreatment conditions with seven subjects in each condition. The drug-treatment groups were drug-drug (D-D), drug-no drug (D-ND), no drug-drug (ND-D), and no drug-no drug (ND-ND). On the first day of training, the inescapable-shock groups received their respective drug treatments and $10 \mathrm{~min}$ after injection the rat was placed in the inescapable shock chamber and received 64 1.0-mA shocks of $5 \mathrm{sec}$ duration. Inescapable shock was administered according to an intertrial interval schedule with a range of 5-108 sec and a mean of $55 \mathrm{sec}$. The naive group received their first-day drug treatment and no further pretraining. A restrained, but not shocked, group was previously investigated by Maier et al. (1973). Since that investigation found no significant difference in latencies between the restrained and naive groups, the restrained group was omitted from the present study.

Twenty-four hours later, all rats received their second drug treatment and 30 trials of escape-avoidance training in the shuttlebox. After injection with the prescribed drug treatment, the rat was placed in the shuttlebox for a 10-min adaptation period. Each trial began with a 5-sec buzzer before shock onset. The rat could avoid or escape shock by crossing to the opposite side of the midline made by the archway in the shuttlebox; the buzzer remained on until the trial terminated. If the rat failed to cross during the interval, a $1-\mathrm{mA}$ shock resulted and remained on until the rat crossed the midline. The trial was automatically terminated if the rat failed to cross the shuttlebox within $35 \mathrm{sec}$ of buzzer onset, and a 35-sec latency was recorded. For the first 5 trials, shock was terminated with one crossing of the shuttlebox
(FR-1). For the next 25 trials, shock could be terminated only by two crossings in the shuttlebox (FR-2). The intertrial interval had a range of 5-108 sec and a mean of $55 \mathrm{sec}$.

\section{RESULTS}

Figure 1 presents the mean FR-2 latencies from buzzer onset for each of the eight groups. These means were derived from the average of each animal's latencies for 25 trials. Consistent with previous findings, Maier et al. (1973), FR-1 latencies revealed no significant learned helplessness effect $(t=1.72$, $\mathrm{df}=54, \mathrm{p}>.05)$. The FR-2 data were analyzed by means of a 2 by 2 by 2 by 25 factorial design. There were three between effects of two levels each, shock or no-shock pretreatment, alcohol or no alcohol in pretreatment, and alcohol or no alcohol in the shuttlebox task. The single within effect was of the 25 trials of FR-2 training in the shuttlebox. All data were latencies in seconds. The shock pretreatment main effect was significant $(F=25.02$, $\mathrm{df}=1,48, \mathrm{p}<.01$ ), that is, the learned helplessness effect was significant. There was no significant effect upon the shuttlebox performance of the alcohol pretreatment main effect $(F=.05$, df $=1,48$,

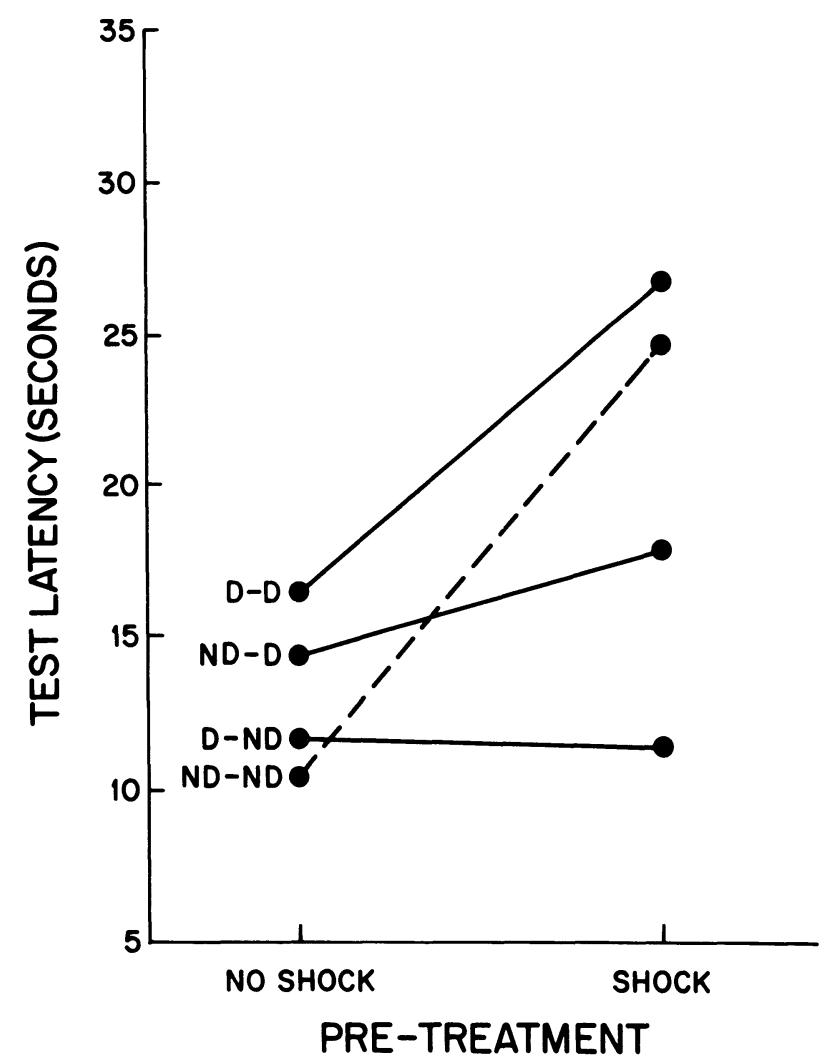

Figure 1. Mean FR-2 avoidance latency for the groups receiving inescapable shock pretreatment and those receiving no pretreatment shock for each of the four drug (alcohol) sequences. 
$p>.05)$, but there was a significant main effect of alcohol given in the shuttlebox situation $(F=9.60$, df $=1,48, p<.01$ ); that is, there was no simple drug effect of alcohol in pretreatment upon the subsequent FR-2 escape-avoidance learning, but there was a depressive effect of alcohol upon the shuttlebox performance per se.

There was a significant interaction between the pretreatment drug effect and the shuttlebox drug effect $(F=16.84, \mathrm{df}=1,48, \mathrm{p}<.01)$, indicating statedependent learning. Thus, shifts in drug states from the pretreatment to the shuttlebox situation diminished the learned helplessness effect, while similar drug states between the pretreatment and shuttlebox situations maintained the learned helplessness effect. This state-dependent learning effect resembles the asymmetrical effect observed in 2 by 2 state-dependent learning studies; that is, the drug-to-no-drug progression from pretreatment to shuttlebox produced a greater disruption of learned helplessness than the no-drug-to-drug progression. Due to the type of training measures involved with learned helplessness as compared to training procedures employed in typical state-dependent studies, the asymmetry of the ND-D and D-ND groups cannot be directly compared. However, comparisons were conducted between mean latencies computed from the combined ND-D no-shock (naive) group and ND-D inescapable shock group with the D-ND no-shock and inescapable shock groups $(\mathrm{t}=3.26, \mathrm{df}=26, \mathrm{p}<.01)$.

The triple-order interaction of learned helplessness (pretreatment shock) by state-dependent learning (drug state shift) was significant $(\mathrm{F}=14.55, \mathrm{df}=1,48$, $\mathrm{p}<.01)$. This is interpreted as a dependency of the learned helplessness effect upon the similarity of drug states. That is, if the drug states were similar in the pretreatment and shuttlebox situation, learned helplessness was augmented. If the drug states were dissimilar, learned helplessness was diminished. The within variable, the 25 trials of FR-2 escape-avoidance conditioning, was not significant $(F=1.61, p>.05)$, nor were any other interactions. Thus, although there was no significant change in latency within the 25 trials of the FR-2 test, the latencies between groups differed, indicating learning due to the 24 -h prior shock experiences.

\section{DISCUSSION}

The results are consistent with those of Maier et al. (1973) of interference in learning the FR-2 shuttlebox tasks by rats previously subjected to inescapable and uncontrollable electric shock. Also congruent with earlier findings by Maier et al. (1973) was the lack of an effect using FR-1 latencies between subjects receiving inescapable shock and those subjects not exposed to the shock pretreatment. The results are
Table 1

Summary of the 2 by 2 by 2 by 25 ANOVA

\begin{tabular}{lrrc}
\hline \multicolumn{1}{c}{ Source } & df & Sum of Squares & $\mathrm{F}$ \\
\hline Pretreatment Shock $\left(\mathrm{B}_{1}\right)$ & 1 & 16774.1 & $25.02^{*}$ \\
Alcohol in Pretreatment $\left(\mathrm{B}_{2}\right)$ & 1 & 33.1 & .05 \\
$\mathrm{~B}_{1}$ by $\mathrm{B}_{2}$ & 1 & 1336.9 & 1.99 \\
Alcohol in Shuttlebox $\left(\mathrm{B}_{3}\right)$ & 1 & 6437.1 & $9.60^{*}$ \\
$\mathrm{~B}_{1}$ by $\mathrm{B}_{3}$ & 1 & .1 & .00 \\
$\mathrm{~B}_{2}$ by $\mathrm{B}_{3}$ & 1 & 11292.3 & $16.84^{*}$ \\
$\mathrm{~B}_{1}$ by $\mathrm{B}_{2}$ by $\mathrm{B}_{3}$ & 1 & 9756.9 & $14.55^{*}$ \\
${\mathrm{Trials}\left(\mathrm{W}_{1}\right)}_{\mathrm{W}_{1} \text { by } \mathrm{B}_{1}}^{24}$ & 1812.0 & 1.62 \\
$\mathrm{~W}_{1}$ by $\mathrm{B}_{2}$ & 24 & 919.0 & .82 \\
$\mathrm{~W}_{1}$ by $\mathrm{B}_{1}$ by $\mathrm{B}_{2}$ & 24 & 697.3 & .62 \\
$\mathrm{~W}_{1}$ by $\mathrm{B}_{3}$ & 24 & 1097.3 & .98 \\
$\mathrm{~W}_{1}$ by $\mathrm{B}_{1}$ by $\mathrm{B}_{3}$ & 24 & 1423.6 & 1.27 \\
$\mathrm{~W}_{1}$ by $\mathrm{B}_{2}$ by $\mathrm{B}_{3}$ & 24 & 1058.2 & .94 \\
$\mathrm{~W}_{1}$ by $\mathrm{B}_{1}$ by $\mathrm{B}_{2}$ by $\mathrm{B}_{3}$ & 24 & 706.8 & .63 \\
${ }^{*}$ & 24 & 880.1 & .79 \\
\hline
\end{tabular}

${ }^{*} p<.01$.

in keeping with earlier studies of the effects of alcohol upon retention of shuttlebox avoidance responses (Crow, 1966; Holloway, 1972), with the exception of the direction of the effects of drug state shifts. That is, in the present study with inescapable shock, dissimilar drug state sequences enhanced avoidance conditioning, whereas in previous studies without inescapable shock, dissimilar drug state sequences impaired avoidance responding. In this and in previous studies of the rat's avoidance learning, the drug state transfer was asymmetrical.

As stated above, the slopes of the asymmetrical effect obtained in the drug-to-no-drug and no-drugto-drug progression for subjects receiving inescapable shock pretreatment could not be directly compared. That is, in the training sequence for learned helplessness, subjects are first given inescapable shock in the restraining chamber while under a drug state, this type of procedure generating no measurable data, i.e., latencies in seconds. Then subjects are introduced for the first time to the 25 FR-2 escape-avoidance trials in the shuttlebox. By contrast, in state-dependent learning studies, subjects are trained to avoidance in the shuttlebox while under a specific drug state. The subjects are then tested in a similar or dissimilar drug state for retention or disruption of the learned avoidance response. This type of procedure allows for the direct comparison of the D-ND and ND-D asymmetrical effect as the training situation, as well as the testing situation, yields data that can be compared.

The results are believed to support the notion that alcohol state transfer effects across those learning tasks here under discussion are due to associative, as opposed to nonassociative, drug effects. This belief is based upon the enhanced avoidance responding with drug state shifts seen in the present study when compared to the impaired effect of drug state shifts 
in the standard 2 by 2 state-dependent learning design. That this associative effect is one involving memory retrieval, as opposed to the storage processes of memory, is supported by the indication of asymmetry. Some kind of habituation of the emotional responses to the cues associated with shock may be interfered with by the alcohol (Crow \& Watkins, 1976). In the learned helplessness paradigm, as opposed to the standard 2 by 2 state-dependent learning design, little other than emotional responses is possible in the inescapable shock pretreatment.

Alcohol was found to intensify learned helplessness in the situation in which both pretreatment shock and subsequent demands for new learning occurred under intoxication. In light of this, even though the group receiving alcohol in the pretreatment condition did not display helplessness when tested in a sober state, the findings do not necessarily indicate that alcohol diminished fear and depression, the emotional sequence involved according to Seligman (1975). The shift from alcohol in pretreatment to the noalcohol state in the shuttlebox may have altered the previously associated emotional response to inescapable shock by disrupting its retrieval.

\section{REFERENCES}

Altenor, A., KAy, E., \& Richter, M. The generality of learned helplessness in the rat. Learning and Motivation, 1977, 8, 54-61.

Crow, L. T. Effects of alcohol on conditioned avoidance responding. Physiology \& Behavior, 1966, 1, 89-91.

Crow, L. T., \& BALL, C. Alcohol state-dependency and autonomic reactivity. Psychophysiology, 1975, 12, 702-706.

Crow, L. T., \& W ATKins, C. H. Alcohol state-dependent cues in avoidance learning. Bulletin of the Psychonomic Society, 1976, 7, 249-250

Hollowa $\%$ F. A. State-dependent effects of ethanol on active and passive avoidance learning. Psychopharmacologia (Berlin) 1972, 25, 238-261.

Kalant, H. Absorption diffusion, distribution and elimination of ethanol: Effects on biological membranes. In B. Kissin
\& H. Begleiter (Eds.), The biology of alcoholism (Vol. 1) Biochemistry. New York: Plenum, 1971.

Linakis, J. G., \& Cunningham, C. L. Effects of concentration of ethanol injected intraperitoneally on taste aversion, body temperature, and activity. Psychopharmacology, 1979, 64, 61-65.

Maier, S. F., Albin, R. W., \& Testa, T. J. Failure to learn to escape in rats previously exposed to inescapable shock depends on the nature of escape response. Journal of Comparative and Physiological Psychology, 1973, 85, 581-592.

Maier, S. F., \& Seligman, M. E. P. Learned helplessness: Theory and evidence. Journal of Experimental Psychology: General, 1976, 105, 3-46.

Maier, S. F., Seligman, M. E. P., \& Solomon, R. L. Pavlovian fear and conditioning and learned helplessness. In B. A. Campbell \& R. M. Church (Eds.), Punishment and aversive behavior. New York: Appleton-Century-Crofts, 1969.

Maier, S. F., \& Testa, T. J. Failure to learn to escape by rats previously exposed to inescapable shock is partly produced by associative interference. Journal of Comparative and Physiological Psychology, 1975, 88, 554-564.

Overton, D. A. State-dependent or dissociated learning produced with pentobarbital. Journal of Comparative and Physiological Psychology, 1964, 57, 3-12.

Ove RTon, D. A. State-dependent or dissociated learning produced by depressant and atropine-like drugs. Psychopharmacologia (Berlin), 1966, 10, 6-31.

Powell, B. J., Goodwin, D. W., Janes, C. L., \& Hoine, H. State-dependent effects of alcohol on autonomic-orienting responses. Psychonomic Science, 1971, 25, 305-306.

Rosellini, R. A., \& Seligman, M. E. P. Failure to escape shock following repeated exposure to inescapable shock. Bulletin of the Psychonomic Society, 1976, 7, 251-253.

Seligman, M. E. P. Helplessness: On depression, development and death. San Francisco: Freeman, 1975.

Seligman, M. E. P., \& Beagley, G. Learned helplessness in the rat. Journal of Comparative and Physiological Psychology, 1975, 88, 534-541.

Seligman, M. E. P., Rosellini, R. A., \& Kozak, M. J. Learned helplessness in the rat: Time course, immunization and reversibility. Journal of Comparative and Physiological Psychology, 1975, 88, 542-547.

Weingartner, H., Eich, J. E., \& Allen, R. Alcohol statedependent associative processes. Proceedings of the American Psychological Association, 1973, 1009-1010.

(Received for publication May 31, 1978; revision accepted September 17, 1979.) 